LITERATURA 



\section{REESCRIBIENDO A MILTON: SEIS SONETOS EN ESPAÑOL}

Santiago García-Castañón

\section{(ब) $\Theta \Theta$}

Esta obra está bajo una licencia Creative Commons

Reconocimiento-No Comercial-Sin Obra Derivada 



\title{
REESCRIBIENDO A MILTON: SEIS SONETOS EN ESPAÑOL
}

\author{
RE-WRITING MILTON: SIX SONNETS IN SPANISH
}

Santiago García-Castañón

\begin{abstract}
RESUMEN
No existe en la actualidad en el mercado ninguna traducción solvente de los sonetos de Milton al español manteniendo la rígida estructura formal del soneto. El presente trabajo, que ofrece traducciones de seis de ellos, es un acercamiento contextualizado a la traducción integral de los sonetos de John Milton al español en verso.

Palabras clave: John Milton, poesía, sonetos, traducción, verso español.
\end{abstract}

\section{ABSTRACT}

There is currently no adequate translation of Milton's sonnets into Spanish, maintaining the rigid formal structure of the sonnet. The present article, which includes translations of six of them, is an initial contextualized approach to the holistic translation of John Milton's sonnets into Spanish verse. Key words: John Milton, poetry, sonnets, translation, Spanish verse.

La extensa y variada producción literaria de John Milton (1608-1674) se ha visto oscurecida, sobre todo fuera del ámbito anglófono, por su obra maestra, Paradise Lost, que lo ha encumbrado como el segundo autor inglés del siglo XVII (y acaso de todos los tiempos), solo por detrás de Shakespeare. La vida de Milton comienza en Londres, en el seno de una rígida familia de origen católico. Su padre era un escribano de buena posición aficionado a la música e introducido en los ambientes culturales londinenses. Desde su adolescencia fue

Dr. Santiago García-Castañón. Western Carolina University. Profesor catedrático de Literatura Española. Estados Unidos.

Correo electrónico: sgarcia@email.wcu.edu

Recepción: 14- 04- 2016

Aceptación: 25- 05- 2016 
instruido en lenguas clásicas y a los 16 años ingresó en el prestigioso Christ's College de Cambridge. Tras su graduación en 1632, Milton se recluyó durante los seis años siguientes para dedicarse al estudio y la escritura. En 1638 abandonó este encierro voluntario para viajar por Francia e Italia. En la primavera de 1639, durante su estancia en Nápoles, recibió noticias de la turbulenta situación de su país, por lo cual decidió interrumpir su estancia en Italia y regresar a Inglaterra, adonde llegó en julio o agosto de ese año. Por esas fechas, con una Inglaterra en ambiente de pre-guerra civil, Milton escribió varios tratados vehementes en contra de las jerarquías de la Iglesia Anglicana y en defensa de la moral; entre estas obras destacan $O f$ Reformation Touching Church Discipline in England (1641) y Of Prelatical Episcopacy y The Reason of Church-Government Urged against Prelaty.

En la primavera de 1642, John Milton, de 33 años de edad, contrajo matrimonio con Mary Powell, que apenas tenía 16. Un mes después, incapaz de convivir con su esposo, Mary se ausentó del hogar y no regresó en tres años. Durante esa larga separación, Milton se convirtió en un ardiente defensor del divorcio (consideró la posibilidad de divorciarse, aunque no llegó a hacerlo) y escribió Doctrine and Discipline of Divorce (1643) y The Judgement of Martin Bucer Concerning Divorce (1644), que le ocasionaron la reprobación de la Iglesia y de gran parte de sus conciudadanos. Pero Mary regresó y, ya reconciliados, el matrimonio tuvo dos hijas, Anne (1646) y Mary (1648).

La lucha por el poder entre Carlos I y el Parlamento desembocó en un proceso judicial contra el monarca a principios de 1649. Carlos I fue sometido a juicio acusado de traición y, declarado culpable el 26 de enero, fue decapitado cuatro días después. Milton se había mostrado partidario del Parlamento y en este contexto produjo varios tratados de carácter político, alguno de ellos en defensa de la ejecución del rey, como The Tenure of Kings and Magistrates (1649). Con el nuevo gobierno de Cromwell, Milton ocupó el cargo de Secretario de Lenguas Extranjeras, al tiempo que siguió escribiendo diatribas contra la monarquía y a favor del parlamentarismo. Su célebre Eikonoklastes es una encendida defensa del regicidio.

El glaucoma que Milton venía padeciendo desde tiempo atrás desembocó en una pérdida total de la visión en 1652. Su ceguera le provocó una profunda crisis existencial; por un lado, le incapacitaba para escribir y tuvo que hacerlo al dictado sirviéndose de amanuenses, uno de los cuales fue el célebre poeta Andrew Marvell; por otro lado Milton consideraba que su ceguera podía deberse a una prueba a la que Dios lo sometía y que debía llevar con cristiana resignación. A esta época pertenece el soneto "When I Consider How My Light is Spent", seguramente el poema corto más famoso de Milton. Y como las desgracias nunca vienen solas, también ese mismo año murieron su esposa y su hijo John, de apenas un año de edad.

En 1656 Milton contrajo nuevas nupcias con Katherine Woodcock y un año después nació su hija Katherine, pero su felicidad duró muy poco tiempo, porque en 1658 fallecieron ambas, la madre y la hija, dejando a Milton sumido en la soledad y la depresión. En memoria de su segunda esposa, Milton escribió el soneto "Methought I saw my late espoused saint".

Con la muerte de Oliver Cromwell en 1658, la fortuna de Milton no hizo sino empeorar. Sus obras propagandísticas A Treatise of Civil Power (1659) y Ready and Easy Way To Establish a Free Commonwealth (1660) tampoco contribuyeron a mejorar su situación tras la restauración monárquica de 1660. Temiendo por su seguridad, Milton vivió varios meses oculto hasta que, descubierto, fue arrestado y sometido a juicio, del que seguramente no habría salido con vida de no ser por la providencial intervención de su viejo amigo Andrew Marvell, miembro del Parlamento y figura influyente del reinado de Carlos II. 
En 1663, a la avanzada (para la época) edad de 55 años, totalmente ciego y dos veces viudo, Milton contrajo nuevas nupcias, esta vez con Elizabeth Minshull, una joven de 24 años, en contra de la opinión de sus hijas. Por estas fechas concluyó su obra maestra, Paradise Lost (1667), que hubo de escribir al dictado y cuyos derechos de publicación vendió por la cantidad de mil libras. A esta obra siguieron History of Britain (1670), Paradise Regained y Samson Agonistes (1671) y Of True Religion and Poems, \&c. upon Several Occasions (1673).

John Milton, gloria de las letras inglesas, murió en noviembre de 1674 a causa de la gota: "...the distemper that troubled him the most of any other was the gout, of which he dy'd without much pain in the year of the birth of Christ 1674, and in the six and sixtieth of his age." (Toland, 1761, p. 137). Su entierro en St. Giles contó con la presencia masiva de amigos y admiradores: "All his learned and great Friends in London, not without a friendly concourse of the Vulgar, accompany'd his body to the church of St. Giles near Cripplegate, where he lies buried in the chancel..." (Toland, 1761, p. 137).

John Milton fue un hombre de una cultura extraordinaria: había recibido una rigurosa formación humanística; además de su idioma, hablaba y escribía correctamente en latín, griego, hebreo e italiano y también poseía sólidos conocimientos de francés, español, alemán y arameo. Durante muchos años Milton ocupó el lugar de honor como el mejor autor en lengua inglesa de todos los tiempos. Todavía hoy, las voces autorizadas de muchos críticos consideran a Milton, no a Shakespeare, el mejor poeta en lengua inglesa. Su obra literaria se extiende por un período fascinante y convulso de la historia de Inglaterra, desde Isabel I, Jacobo VI de Escocia y I de Inglaterra, Carlos I, pasando por la Guerra Civil (1642-48), la Commonwealth (1649-53) y el Protectorado de Cromwell (1654-60), hasta la Restauración de la monarquía en la persona de Carlos II (1660).

Su producción prosística se centra en las dos décadas que van de 1640 a 1660 y es altamente panfletaria y polemizante. En estas obras aboga por la libertad de conciencia pero muestra una profunda animadversión por el catolicismo. A pesar de que sus libros en prosa tuvieron gran influencia en su tiempo, Milton siempre se mostró más orgulloso de su obra poética y se refería jocosamente a su prosa como el producto de su mano izquierda. Sus poemas vieron la luz por vez primera en 1645 con el volumen Poems of Mr. John Milton, Both English and Latin, que contiene poemas de juventud y deja entrever una voz poética personal con gran dominio de la técnica y sólidos conocimientos de la poesía clásica greco-latina y de la italiana contemporánea. Este libro contiene veintiocho poemas, entre ellos diez sonetos, cinco en inglés y cinco en italiano. En 1673, apenas un año antes de su muerte, apareció una segunda edición ampliada, en la que se incluían otros nueve sonetos más. Además de estos diecinueve, hay otros cinco sonetos, uno de ellos con estrambote, dispersos y sin numeración. Algunos críticos le atribuyen erróneamente la autoría de veinticinco sonetos, pero hay un "soneto" que no lo es. R. F. Hall afirma:

\footnotetext{
The body of work known as Milton's sonnets comprises twenty-five poems: twenty-three fourteen-line sonnets (five in Italian, eighteen in English); one fifteen-line canzone in Italian; and one English "tailed" sonnet (the twenty-line 'On the New Forcers of Conscience') (Hall, 1999, p. 98)
}

Por lo tanto si uno de los "sonetos" es una canzone, de quince versos y esquema métrico diferente del que ha de tener un soneto, entonces es eso: una canzone y no un soneto. ${ }^{1}$ Más atinado está Roy Flannagan, quien reconoce la diferencia entre ambas formas poéticas: "He also practiced poetry in the longer, looser Italian form of the canzone, a more elaborate lyric 
or emotional song sometimes built on sonnet structure [...] Milton wrote an Italian canzone as well, dedicated to what seems to be an imaginary woman..." (Flannagan, 2002, pp. 45-47).

La crítica no siempre ha sido benévola con Milton. A finales del XVIII la estética neoclásica no comprendió el alcance de esa poesía con ciertos excesos verbales y más de un fuego de artificio. El más prestigioso crítico de la época, Samuel Johnson, le da un buen varapalo en su Life of Milton, de cuyos poemas dice que de los mejores solo puede decirse que no son malos... y apenas salva dos de los sonetos de Milton: "They deserve not any particular criticism; for of the best it can only be said that they are not bad; and perhaps only the eighth and the twenty-first are truly entitled to this slender commendation." (Johnson, 1925, p. 99) Este crítico neoclásico, que gozó de enorme reputación en vida, está totalmente condicionado por sus gustos personales, que eran los de la estética de su tiempo, y no alcanza a entender las virtudes de un poeta del siglo anterior:

\begin{abstract}
the English poems, though they make no promises of Paradise Lost, have this evidence of genius, that they have a cast original and unborrowed. But their peculiarity is not excellence: if they differ from verses of others, they differ for the worse; for they are too often distinguished by repulsive harshness; the combinations of words are new, but they are not pleasing; the rhymes and epithets seem to be laboriously sought and violently applied... (Johnson, 1925, p. 95)
\end{abstract}

\title{
1. Sobre el estilo de Milton y las traducciones
}

Milton emplea el encabalgamiento con profusión en sus sonetos, hasta el punto de que frecuentemente la ruptura sintáctica no solo cruza los límites del verso, sino incluso los de la estrofa, pasando de un cuarteto a otro o de un cuarteto a un terceto. En estos casos, y con el fin de hacer más comprensible el poema, traté de contener algunos de estos encabalgamientos y crear pausas donde no las había en el original. Comprendo que es un criterio totalmente subjetivo, pero me pareció una solución tan válida como la de mantener las violentas rupturas sintácticas miltonianas.

El endecasílabo italiano encuentra acomodo en la poesía inglesa del siglo XVII en forma de pentámetro yámbico, consistente en cinco pies de dos sílabas (átona-tónica), con resultado de diez sílabas gramaticales y verso oxítono, que es lo más parecido al endecasílabo italiano o español (10+1). La traducción o reescritura de los sonetos de Milton en español constituye un viaje de retorno a los orígenes. Las variedades del endecasílabo español que mejor se prestan son el enfático, el heroico y el melódico; es decir, los que llevan el acento en la sexta sílaba, además del acento versal obligado en la décima. Un reto de más complicada solución es la mayor economía verbal del inglés (vocablos más breves, empleo de menos artículos...), con lo que en un pentámetro yámbico de diez sílabas gramaticales "cabe más" que en un endecasílabo español. Ello presenta para el traductor dos alternativas: o conservar el sentido original resultando versos mucho más largos o, si se quiere conservar el endecasílabo (como es mi caso), buscar una mayor concisión expresiva dejando fuera elementos verbales del original pero que puedan ser prescindibles, aun a costa de alterar ligeramente el significado particular de cada verso. Esta es la ruta que he decidido seguir. Soy consciente de que al hacerlo me veo obligado a desvirtuar el significado del poema, pero es un precio que estoy dispuesto a pagar. En realidad, mi propósito no es tanto traducir los sonetos de Milton como reescribirlos.

Si partimos de la premisa de que el "soneto" debe "sonar", se hace necesario jugar con los significantes para hacer que la mayor concisión léxica y sintáctica del inglés quepa en los límites del endecasílabo, teniendo en cuenta la mayor ampulosidad verbal de la lengua 
española, como se dijo arriba. Por este motivo, en ocasiones opté por sacrificar el significado en beneficio de significante, o lo que es lo mismo: alterar el sentido para mantener la forma. Esto, que podría parecer una aberración, es -en mi opinión- un recurso legítimo en la traducción poética, que es en realidad una forma de reescritura más que un mero ejercicio mecánico.

Alguien dijo que si el poema original es un plato con aspecto, aroma y sabor, el traductor a veces se ve obligado a elegir lo que desea mantener, sabiendo que no podrá conservar los tres. Al haber optado por mantener la forma, he considerado que el aspecto era importante. Creo que se ha logrado conservar el sabor, lo esencial de cada poema, pero me he permitido licencias en cuanto al aroma.

No es fácil librarse del maleficio que rodea al traductor desde la vieja sentencia italiana de "traduttore, traditore". En cierto modo, una traducción es una forma de crítica del original. Es tarea del traductor poner de relieve las principales cualidades de la obra, entendiendo que será imposible captar todos los matices del original, con lo cual es perfectamente válido dejar fuera otros elementos que puedan ser prescindibles. En definitiva, la traducción de un poema debe ser igualmente un poema, esto es, una obra de arte bien confeccionada.

Ezra Pound, excelente traductor además de poeta, defendía la primacía de la recreación poética sobre la mera traducción mecánica: "There must be of course a plain literal version somewhere available, with explanations and notes, however tiresome and unpoetic. There should also be the best available translation of poetic values, in whatever European language this may have been attained" (Pound, 1939, p. 475). Pero Pound tampoco fue ajeno a las críticas por su falta de "fidelidad" al original, ya que consideraba la traducción como una forma de reescritura. ${ }^{2}$ Es bien sabido que cualquiera que posea unos mínimos conocimientos de otra lengua puede producir una versión literal (o incluso sin ellos, ya que hay múltiples traductores electrónicos capaces de hacer un mal trabajo en este sentido). A veces una traducción que se aleja del texto original es más fiel, al menos en el sentido poético, al espíritu del poema mismo. El traductor de poesía, a diferencia de quien traduce un texto científico, legal o de otra índole, debe dotar al poema de una nueva vida en el idioma que será su nuevo "hogar", de modo que el producto final pueda leerse como un poema, y no como la mera traducción de un texto. Por todo ello, no me he sentido obligado a traducir verbatim los contenidos, porque también se hacía necesario traducir la forma; quiero decir que mi principal propósito fue dar como resultado sonetos aceptables en lengua española, y al hacerlo se me antojó hacer diversos cambios, pecado venial que espero me sea perdonado.

En todos los casos ofrezco entre paréntesis el primer verso en la versión inglesa para que el lector pueda acudir al original, si así lo desea.

\section{Seis sonetos}

\section{1 ("When Faith and Love which parted from thee never...")}

Milton escribió el soneto "When Faith and Love which parted from thee never..." (Leonard, XIV, p. 83) $)^{3}$ con ocasión de la muerte de Catharine Thomason (†1646), piadosa y culta dama casada con el librero George Thomason, que era buen amigo del poeta. En su tratado póstumo De Doctrina Christiana, Milton declara que la fe consiste en el conocimiento de Dios y el amor en su adoración. En ese soneto Milton destaca las virtudes de la finada, destacando en ella la fe y el amor ("caritas"), dos de los pilares de la teología protestante. 


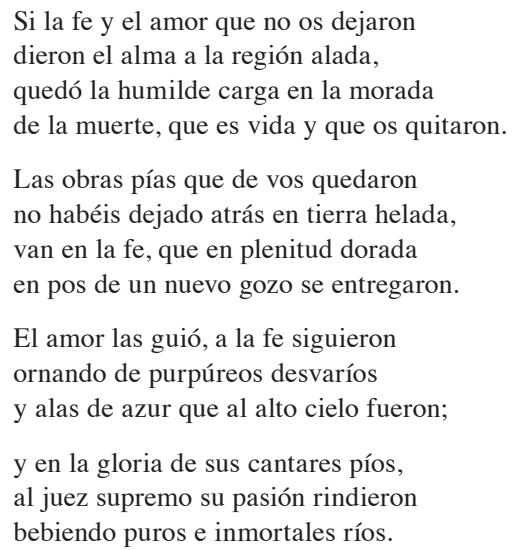

\section{2 (“Avenge O Lord thy slaughtered saints, whose bones...")}

El soneto "A la masacre del Piamonte" ("Avenge O Lord thy slaughtered saints, whose bones..."; Leonard, XV, p. 84) hace referencia al episodio conocido como la masacre de los waldenses, ocurrido en la región alpina del Piamonte. El movimiento waldense surgió a finales del siglo XII, cuando Peter Waldo (ca. 1140-ca. 1205), un acaudalado comerciante de Lyon, distribuyó su fortuna entre los pobres y predicó la pobreza como vía para la salvación. En el siglo XVI los waldenses abrazaron la reforma protestante y desde entonces fueron considerados por el Papado como una secta herética y sometidos a constantes persecuciones durante los siglos XVI y XVII. Tras múltiples e injustos hostigamientos por parte de las autoridades eclesiásticas, finalmente se encargó al Duque de Saboya que dirigiera una expedición de castigo a las aldeas del Piamonte donde residían los waldenses. En la madrugada del 24 de abril las tropas del duque se lanzaron a una despiadada campaña de saqueos, violaciones, torturas y asesinatos de la que quedan escalofriantes testimonios de la época. Casi dos mil campesinos inocentes fueron masacrados con tal brutalidad que varias naciones europeas, entre ellas Inglaterra, se ofrecieron a acoger a los pocos supervivientes. El soneto de Milton se refiere a este sangriento episodio.

\footnotetext{
"A la masacre de los waldenses en el Piamonte"

Venga, Señor, los muertos que en despojos yacen dispersos en el frío alpino, pues fieles a un mandato tan divino heredaron del padre los hinojos.

No olvides que sus vidas, hoy abrojos, antes fueron rebaño peregrino; piamontesa crueldad les dio destino, madres e hijos en gemidos rojos.

Los valles entre riscos permanezcan alzándose hasta el cielo. El sacrificio sobre el ítalo suelo en que halla abrigo

triple tirano, y de ellos miles crezcan que haciendo de su sangre beneficio, expulsen al idólatra enemigo. ${ }^{4}$
} 


\section{3 ("When I consider how my light is spent...")}

El soneto "When I consider how my light is spent..." (Leonard, XVI, p. 84) es seguramente la composición poética breve más conocida de Milton. El poeta, que padecía un severo glaucoma desde tiempo atrás, perdió totalmente de la visión en 1652. Su ceguera le provocó una profunda crisis existencial, ya que le incapacitaba para escribir y debía hacerlo al dictado sirviéndose de amanuenses, uno de los cuales fue el célebre poeta Andrew Marvell. Sin embargo Milton, hombre de profunda y rígida fe, consideraba que su ceguera podía deberse a una prueba a la que Dios lo sometía y que debía sobrellevar con cristiana resignación. El inicio del soneto "When I consider..." es una fórmula convencional de apertura poemática que emplean otros poetas ingleses de la época y que tiene su origen en Petrarca. ${ }^{5}$

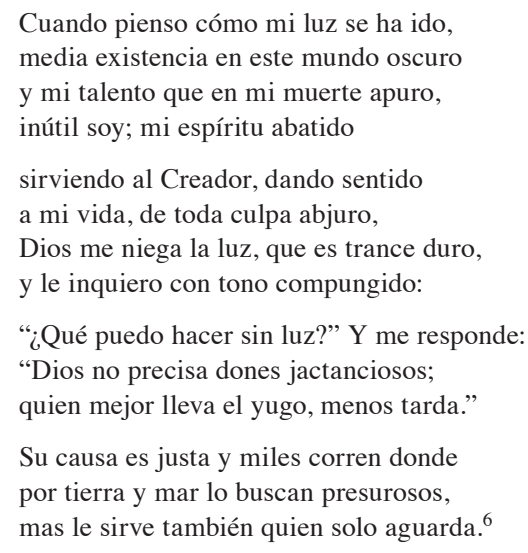

\section{4 ("Methought I saw my late espoused saint...")}

El soneto "Methought I saw my late espoused saint..." (Leonard, XIX, p. 86) es uno de los más personales y desgarradores de Milton. Fue escrito a la muerte de su esposa, aunque existen dudas sobre si se refiere a su primera esposa, Mary Powell, fallecida en 1652, o la segunda, Katherine Woodcock, muerta en 1658. Parece más probable que se trate del segundo supuesto, ya que su relación matrimonial con Mary fue turbulenta, mientras que su matrimonio con Katherine parece haber sido feliz. El poema presenta la visión fantasmagórica de la esposa muerta, que se presenta durante la noche, al igual que Alceste con Admeto, para desaparecer tan pronto como amanece.

\footnotetext{
El rostro vi de mi difunta esposa, devuelta, como Alceste, de la muerte, con que Hércules acrecentó mi suerte, lívida y rescatada de la fosa.

Mía, incólume, limpia, esplendorosa, pura y salvada por la ley tan fuerte, y contemplo su hermoso cuerpo inerte como el que está en el cielo en que reposa.

De blanco a mí llegó toda vestida, cubierto el rostro, y alcanzó a mostrarme que en amor y en bondad resplandecía.

¡Cuánto brillo, reflejo de su vida! Pero ¡ay! que se inclinó para abrazarme y desperté y vi en noche vuelto el día.
} 


\section{5 (“Cromwell, our chief of men, who through a cloud...")}

La oposición de Milton al reinado de Carlos I y su compromiso con la causa del Parlamento le llevaron a escribir varios tratados de contenido propagandístico en favor de Cromwell. Su producción poética también refleja este compromiso político. Escrito en mayo de 1652, el soneto "Al Lord General Cromwell" (Leonard, s/n, p. 113) es un encendido canto en favor del dirigente republicano y hace referencia a las victorias de sus tropas sobre los escoceses en las batallas de Preston (1648), junto al río Darwen, y de Dunbar (1650) y Worcester (1651). Con estas victorias Cromwell consolidó el triunfo de la joven República. El poema considera a Cromwell defensor de la causa divina, de tal modo que sus triunfos son los triunfos de Dios.

\footnotetext{
"Al Lord General Cromwell"?

Cromwell guerrero, en una nube alzado, no solo en el combate victorioso, con fe y con fortaleza sale airoso, y en paz tu sacra senda ha roturado; al cuello de Fortuna coronado, triunfante Dios con celo laborioso, mientras río de sangre corre undoso y en tu loor resuena el grito alzado.

La victoria es final, pero más queda por conquistar aun: la paz que abrazo más que la guerra. Y surgen enemigos atormentando al alma con su rueda: libremos la conciencia del zarpazo de mercenarias fieras y castigos.
}

\section{6 (“Cyriack, this three years' day these eyes, though clear...”)}

El soneto que cierra esta serie lleva el título "To Mr. Cyriack Skinner upon his Blindness" (Leonard, s/n, p. 114) y fue escrito hacia 1655, tres años después de que Milton perdiera la visión. El poema está dedicado al joven Cyriack Skinner (1627-1700), que había sido alumno de Milton, y con quien compartía afición por las letras e ideología política, y era nieto de Sir Edward Coke, prestigioso jurista y amigo personal del poeta. Al igual que su abuelo, Cyriack Skinner también se dedicó a la abogacía y a las letras, y se le atribuye la autoría de The Life of Mr. John Milton, una de las primeras biografías del poeta.

\footnotetext{
“Al Sr. Cyriack Skinner, sobre su ceguera"

Tres años ya mis ojos, que se abrieron a ese mundo exterior sin mancha alguna, privados de la luz y la fortuna, se olvidaron de ver lo que antes vieron.

Ya sol, luna y estrellas se perdieron, hombre y mujer. Disputa inoportuna: contra el poder del cielo no hay ninguna razón, sino bogar donde otros fueron.
}

¿Y preguntas aun qué me sostiene? La conciencia de haberlos empleado en libertad, que es noble causa mía, 
de lo que toda Europa hablando viene.

Esto del mundo vano me ha salvado:

ser ciego mas feliz. No hay mejor guía.

En suma, la breve muestra que aquí se ofrece es un anticipo de lo que será la primera edición de los sonetos completos de Milton en lengua española, manteniendo la rígida estructura del soneto, incluyendo medida, rima, ritmo y otros aspectos métricos. Estos sonetos en versión castellana no pretenden reemplazar la voz del poeta por la del traductor. Se trata, en cualquier caso, de un intento de ofrecer al público lector hispanohablante la oportunidad de leer estas composiciones en verso, precisamente del modo en que fueron escritas. Quien desee apreciar el talento poético de John Milton, sin duda deberá acudir a cualquiera de las fuentes disponibles en la lengua original.

\section{Notas}

1. A pesar de su aparente similitud (algo que ha confundido a más de un crítico), la canzone es una forma poética diferente muy arraigada en la poesía italiana, aunque procedente de la lírica provenzal. Este tipo de poema se desarrolla en Italia durante los siglos XIII y XIV con Dante y Petrarca, respectivamente, y alcanza su mayor esplendor en el cinquecento; se trata de un tipo de poema que se ajusta a las siguientes normas: 1) extensión variable (a diferencia de la rigidez del soneto con 14 versos), 2) combinación de versos heptasílabos y endecasílabos (el soneto tradicional debe estar escrito en endecasílabos), 3) libertad del esquema métrico.

2. Yao, Steven G. (2010). Translation. Por I. B. Nadel (Ed.). Ezra Pound in Context. (33-42).Cambridge: Cambridge University Press.

3. Para comodidad de los lectores, doy aquí la numeración de les adjudica John Leonard, uno de los más solventes editores modernos. Milton, J. (1998). The Complete Poems. (J. Leonard (Ed.)). Londres: Penguin.

4. La expresión "triple tirano" ("triple tyrant") se refiere al papa que ostenta el "triregnum" o triple corona que se usaba desde el siglo XVI y que representaba al pontífice en su triple condición de "pastor universal", "juez eclesiástico" y "gobernante temporal", si bien no existe un acuerdo unánime entre los teólogos, y otros lo explican como "padre de príncipes", "gobernador del mundo" y "vicario de Cristo", o como "sacerdote", "profeta" y "rey". Actualmente el papa no utiliza la tiara de triple corona y su uso se limita a la heráldica de la Santa Sede y a la bandera de la Ciudad del Vaticano.

5. C Cf. Lok: "When I consider of the holy band..."; Shakespeare: "When I consider every thing that grows..."; Dryden: "When I consider life, "tis all a cheat..."; hay abundantes ejemplos de fórmulas similares en nuestra Edad de Oro (Garcilaso, Sebastián de Córdoba, Fray Luis, Salas Barbadillo, Lope de Vega, Quevedo...). En todos los casos se trata de una herencia de Petrarca: "Quand'io mi volgo indietro a mirar gli anni....". Sobre esta fórmula, vid. Nadine Ly (1998), "La reescritura del soneto primero de Garcilaso", Criticón 74; 9.29, y Andrés González Sánchez (2009), “"Cuando me vuelvo atrás a ver los años'. Intertextualidad petrarquiana en Garcilaso, Lope de Vega y Quevedo", Espéctaculo. Revista de Estudios Literarios 43. http://www.ucm.es/info/especulo/numero43/interpet.html

6. Este soneto, acaso el más famoso de cuantos escribió Milton, es una reflexión sobre su ceguera. Milton, que perdió la visión gradualmente, se quedó totalmente ciego a principios de 1652, a la edad de 43 años. El poeta expresa su preocupación por no poder usar su mejor talento (la capacidad de escribir). A la pregunta de qué es posible hacer sin luz, la propia voz de Dios le responde que no es necesario "hacer" nada para agradarle, ya que es suficiente esperar (la esperanza). El verso 3 es una clara referencia a la parábola de los talentos (Mateo 25: 14-30). El "talento" de Milton, su regalo divino, es su capacidad para escribir, algo a lo que el poeta ha consagrado su vida, pero la ceguera le ha arrebatado ese don otorgado por la gracia de Dios. La oscuridad del mundo (en este caso muy real) envuelve al poeta quien siente sus limitaciones para llevar a cabo la tarea encomendada. La claridad llega con la respuesta, reafirmando que Dios no necesita de las obras humanas, sino que el mero deseo de realizarlas es suficiente. Precisamente al sumirse en la ceguera, Milton alcanza a entender que a veces es suficiente con aguardar la gracia divina para alcanzarla. La primacía de la fe sobre las obras humanas fue uno de los temas de divergencia entre católicos y protestantes desde los inicios de la Reforma. 
7. Si bien el cargo político Oliver Cromwell fue el de "Lord Protector", Milton titula este soneto "To the Lord General Cromwell". El poema pone especial énfasis en las victorias bélicas del protagonista, por lo cual se emplea la graduación militar, que Cromwell en efecto poseía.

\section{Bibliografía}

Flannagan, R. (2002). John Milton: A Short Introduction. Oxford: Blackwell.

González-Sánchez, A. (2009). 'Cuando me vuelvo atrás a ver los años'. Intertextualidad petrarquiana en Garcilaso, Lope de Vega y Quevedo. Espéculo. Revista de Estudios Literarios. 43. http://www.ucm.es/info/especulo/numero43/interpet.html [Consultla 21 de mayo de 2016].

Hall, R. F. (1999). Milton's sonnets and his contemporaries. Por D. Danielson (Ed.). The Cambridge Companion to Milton. (98-112). Cambridge: Cambridge University Press.

Hanford, J. H. (1921). The Arrangement and Dates of Milton's Sonnets. Modern Philology. 18 (9), 475-483.

Johnson, S. (1925). Lives of the English Poets. Londres: J. M. Dent \& Sons. (Orig. The Lives of the Most Eminent Poets, 1779-81; 10 vols.).

Jones, E. (1994). Milton's Sonnets: An Annotated Bibliography (1900-1992). Binghamton: Medieval and Renaissance Texts and Studies.

López-García, D. (1991). Sobre la imposibilidad de la traducción. Cuenca: Servicio de Publicaciones de la Universidad de Castilla-La Mancha.

Ly, N. (1998). La reescritura del soneto primero de Garcilaso. Criticón. 74, 9-29.

Milton, J. (1957). Complete Poems and Major Prose. Por M. Hughes (Ed.). Nueva York: Odyssey Press.

Milton, J. (1977). Sonnets. Samson Agonistes / Sonetos. Sansón Agonista. A. Saravia-Santander (Ed.). Barcelona: Bosch.

Milton, J. (1998). The Complete Poems. J. Leonard (Ed.). Londres: Penguin.

Pound, E. (1939). Ezra Pound's Poetry and Prose. Contributions to Periodicals. Nueva YorkLondres: Garland.

Pigott, A. S. (1972). A Variorum Commentary on the Poems of John Milton. Londres: Routledge \& Kegan Paul.

Sampson, A. (1886). Milton's Sonnets. Nueva York: The De Vinne Press.

Teskey, G. (2015). The Poetry of John Milton. Cambridge, MA: Harvard University Press.

Toland, J. (1699). The Life of John Milton. Londres: Impr. J. Darby (reimpr. 1761).

Yao, S. G. (2010). Translation. Por I. B. Nadel (Ed.). Ezra Pound in Context. (33-41). Cambridge: Cambridge University Press. 